\title{
Two for one: endoscopic drainage of a large pyogenic liver abscess at the time of ERCP
}

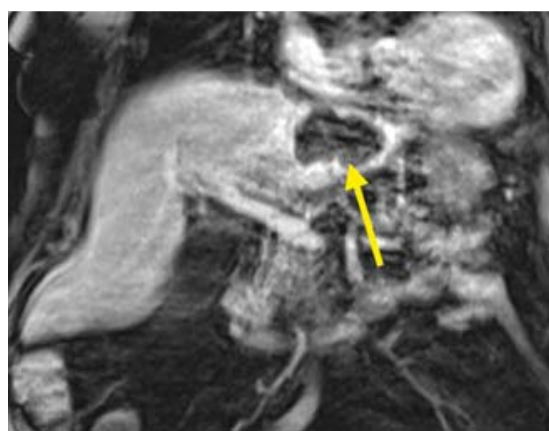

- Fig. 1 Magnetic resonance imaging showing a large liver abscess.

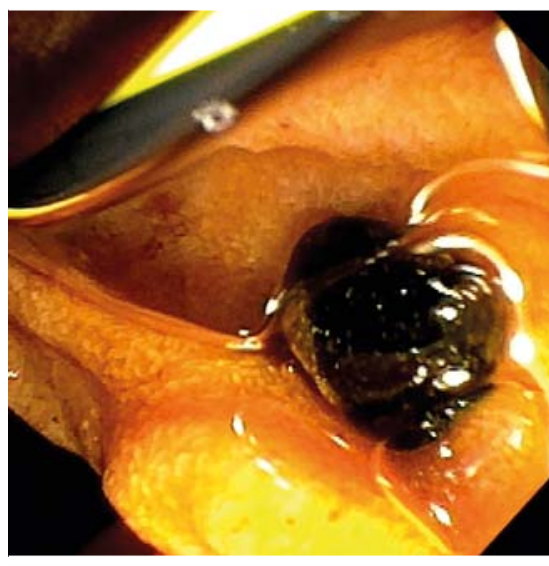

- Fig. 2 A pigment stone removed on endoscopic retrograde cholangiopancreatography.

An 84-year-old man with chronic lung disease on home oxygen, coronary artery disease with coronary stents, and diabetes, presented with right upper quadrant pain and fever. Magnetic resonance imaging was performed that showed choledocholithiasis in a dilated bile duct. Additionally, a large 7-cm fluid-filled cavity was seen in the left lobe of the liver abutting the stomach, consistent with an abscess ( $\triangleright$ Fig. 1). Given the choledocholithiasis and lack of travel history, the presumptive diagnosis was pyogenic liver abscess.

In view of the patient's comorbidities, a single procedure to treat both the cho-

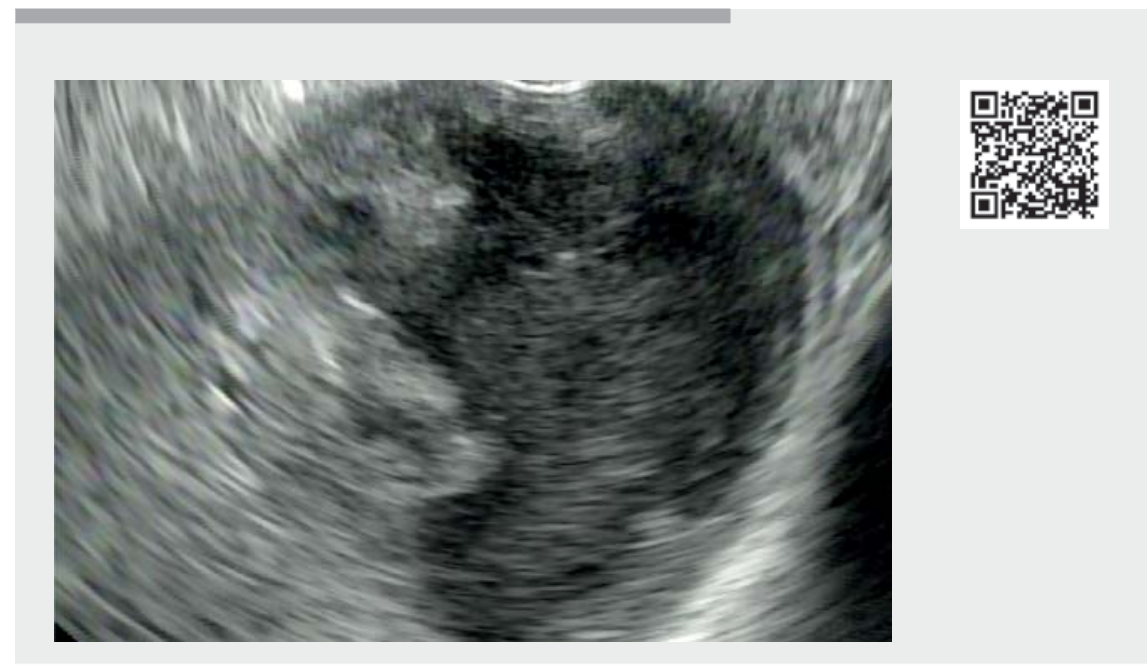

$\checkmark$ Video 1 Endoscopic ultrasound-guided drainage of a large liver abscess.

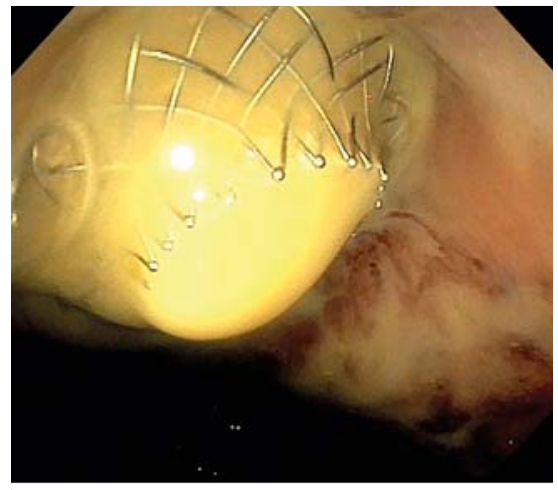

Fig. 3 Endoscopic view of the placed lumen-apposing metal stent draining copious pus from the liver abscess into the stomach.

ledocholithiasis and the liver abscess was preferable. In addition, the size of the abscess necessitated a larger drain. Thus, after multidisciplinary discussion, the decision was made to proceed with endoscopic drainage of the abscess after endoscopic retrograde cholangiopancreatography (ERCP). ERCP was uneventful and pigment stones were removed ( Fig.2). Next, endoscopic ultrasonography (EUS) was performed using a linear

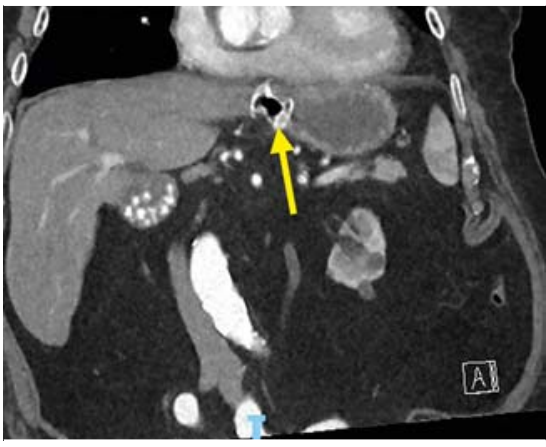

- Fig. 4 Computed tomography scan showing the liver 4 weeks after placement of a lumen-apposing metal stent. The abscess has resolved.

scope. A large heterogeneous collection was seen in the left lobe of the liver abutting the stomach. A 19-gauge aspiration needle was used to aspirate pus, confirming a pyogenic abscess. A 15-mm electrocautery lumen-apposing metal stent was then placed in the usual manner ( $\downarrow$ Video 1 ). Copious pus was seen flowing into the stomach from the distal flange (> Fig. 3 ).

The patient did well and was discharged 5 days later after receiving intravenous 
antibiotics. Four weeks after stent placement, computed tomography showed resolution of the abscess ( $\triangleright$ Fig.4), and the stent was subsequently removed. At 3-month follow-up the patient continued to do well.

Traditionally, pyogenic liver abscesses are drained percutaneously. However, large liver abscesses that are accessible by EUS may benefit from a larger-diameter drain. In addition, if bile duct intervention is required, this case shows that both can be performed at the same time.

Endoscopy_UCTN_Code_TTT_1AS_2AD

Competing interests

AJT: Consultant for Pentax Medical, research support from NinePoint Medical.

PB: Consultant for Olympus America, Boston Scientific, Apollo Overstitch, and Fujifilm.

All other authors have no conflict of interest.
The authors

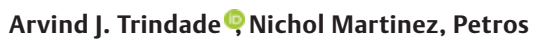
C. Benias, Larry Miller

Division of Gastroenterology, Long Island Jewish Medical Center, Zucker School of Medicine at Hofstra/Northwell, Northwell Health System, New Hyde Park, New York, USA

Corresponding author

\section{Arvind J. Trindade, MD}

Division of Gastroenterology, Long Island Jewish Medical Center, 270-05 76th Ave, New Hyde Park, NY 11040-1496, USA

arvind.trindade@gmail.com

\section{Bibliography}

Endoscopy 2022; 54: E119-E120

DOI 10.1055/a-1408-1304

ISSN 0013-726X

published online 16.4.2021

(c) 2021. Thieme. All rights reserved.

Georg Thieme Verlag KG, Rüdigerstraße 14, 70469 Stuttgart, Germany

\section{ENDOSCOPY E-VIDEOS}

https://eref.thieme.de/e-videos

口回 Endoscopy E-Videos is an Fen access online section, 回: reporting on interesting cases and new techniques in gastroenterological endoscopy. All papers include a high quality video and all contributions are freely accessible online. Processing charges apply (currently EUR 375), discounts and wavers acc. to HINARI are available.

This section has its own submission website at

https://mc.manuscriptcentral.com/e-videos 